\title{
(PFI
}

\section{Optimization of an SOFC-}

based decentralized polygeneration system for providing energy services in an office-building in Tōkyō

C. Weber, F. Maréchal, D. Favrat, S. Kraines, M. Koyama

\section{(Pfl}

Define optimal configurations for an SOFC-based decentralized polygeneration (energy) system:

Providing:

heating, cooling and electricity services to a building

Minimizing:

Total cọsts

$\mathrm{CO}_{2}$-emissions

$\Rightarrow$ Compare with the current situation. 


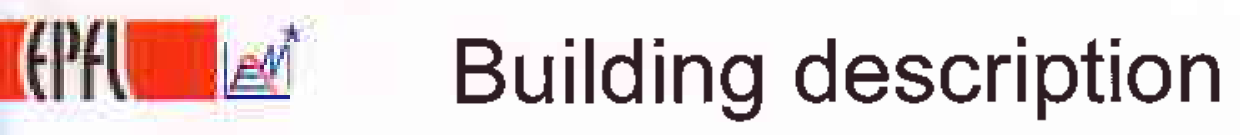

- 10 floors

- 20 offices per floor, $50 \mathrm{~m}^{2}$ per office-room

- 12 working-hours per day

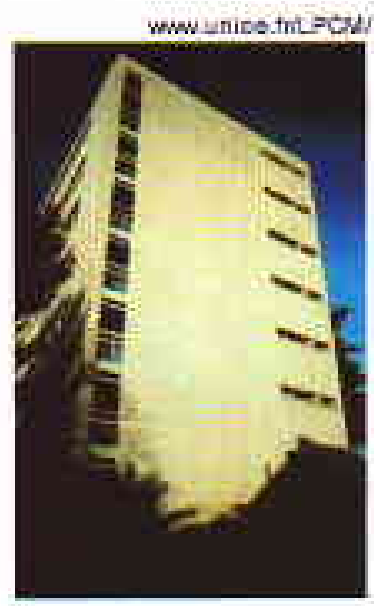

(PFA $\square$ Energy services required throughout the year

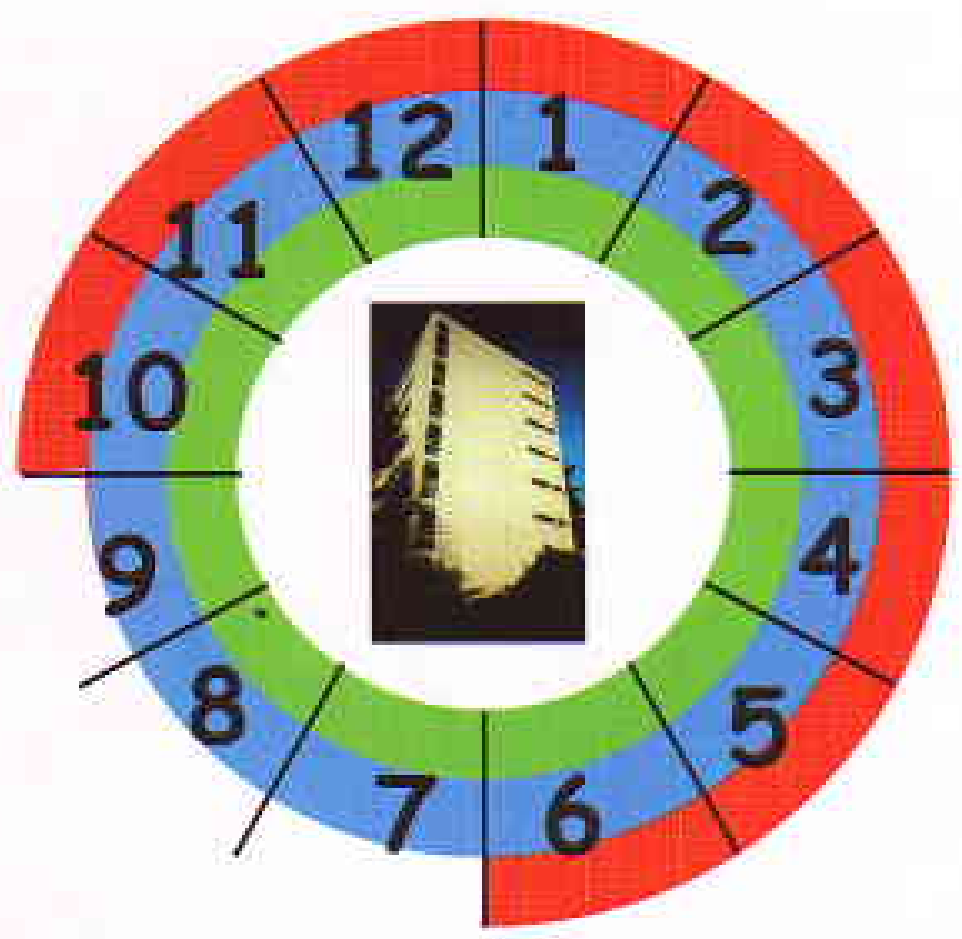

Heating

\section{Cooling}

Electricity 


\section{(PFl Daily consumption profiles}

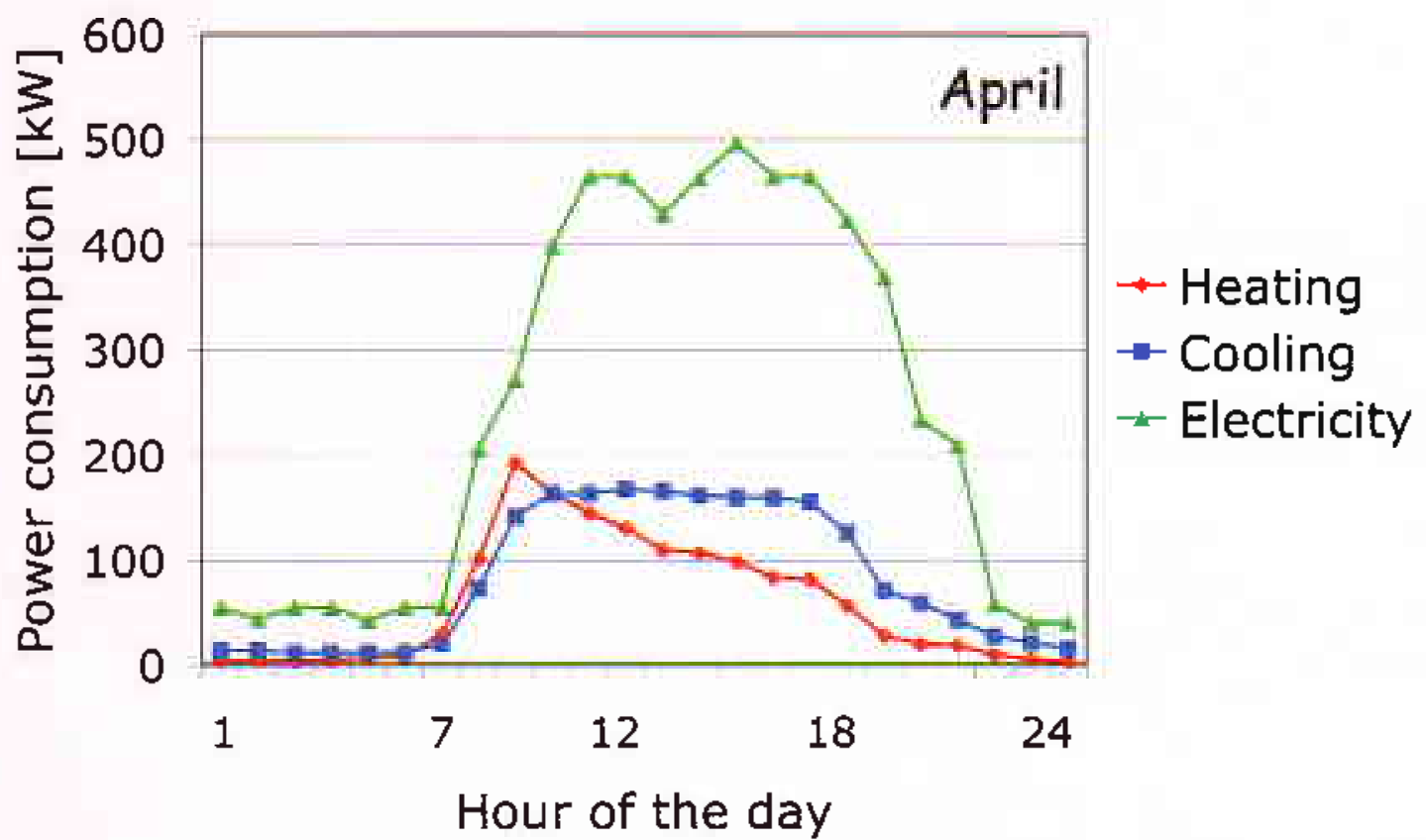

$\Rightarrow$ One daily profile for each energy requirement per month $5 / 15$

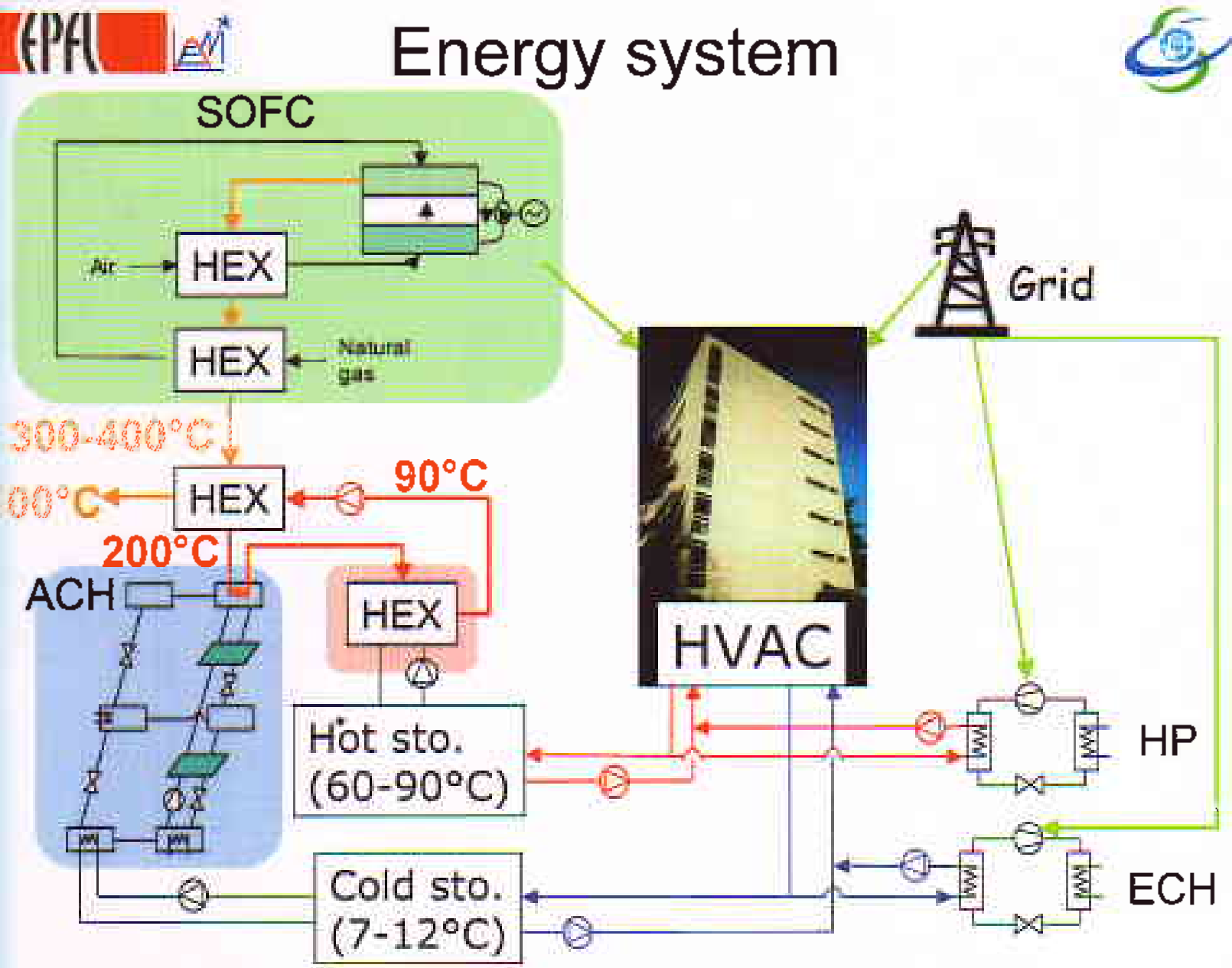




\section{(PFl EN Solid Oxide Fuel Cell (SOFC)}

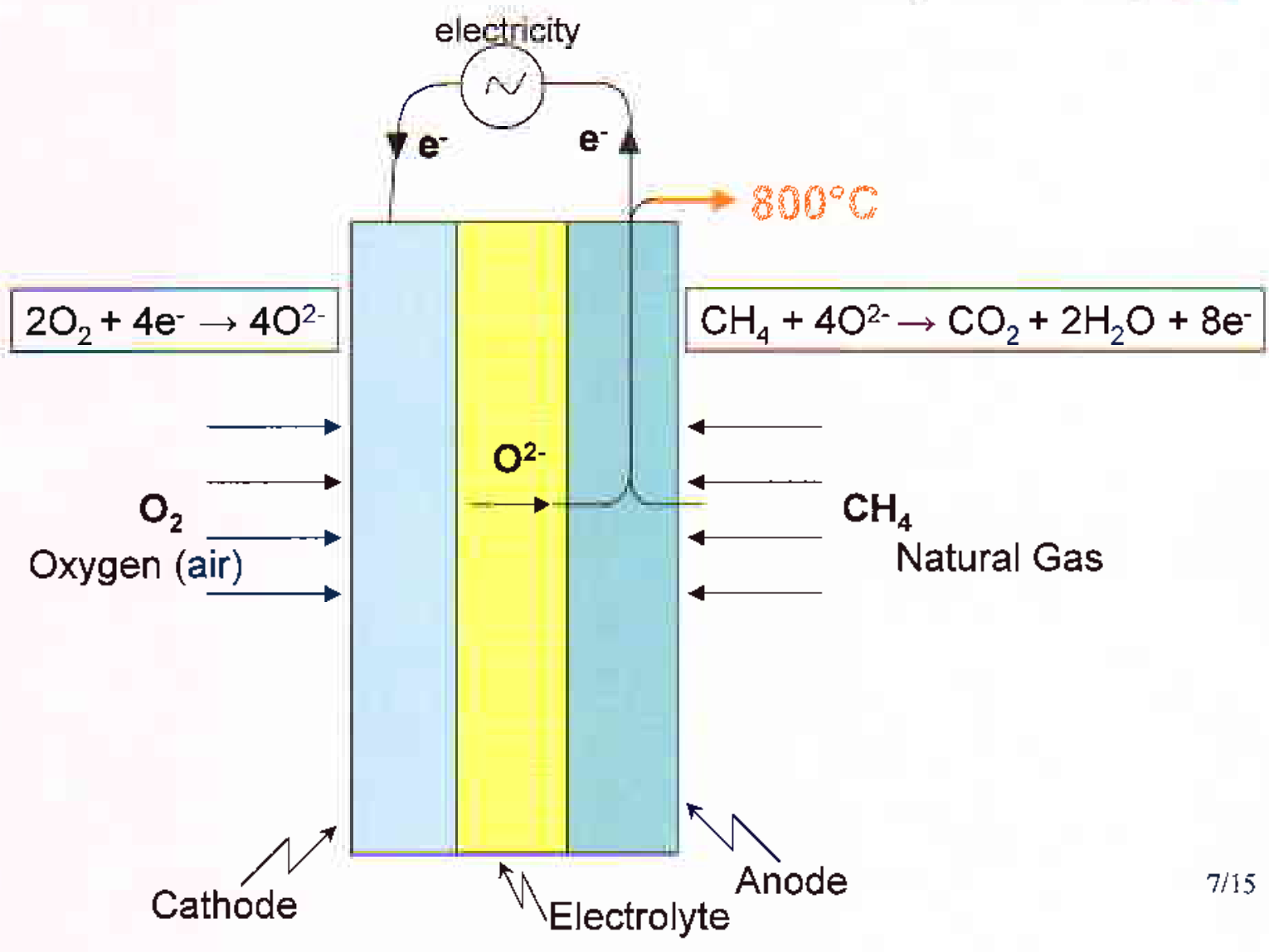

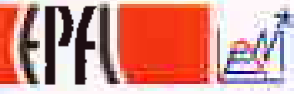

Absorption-chiller

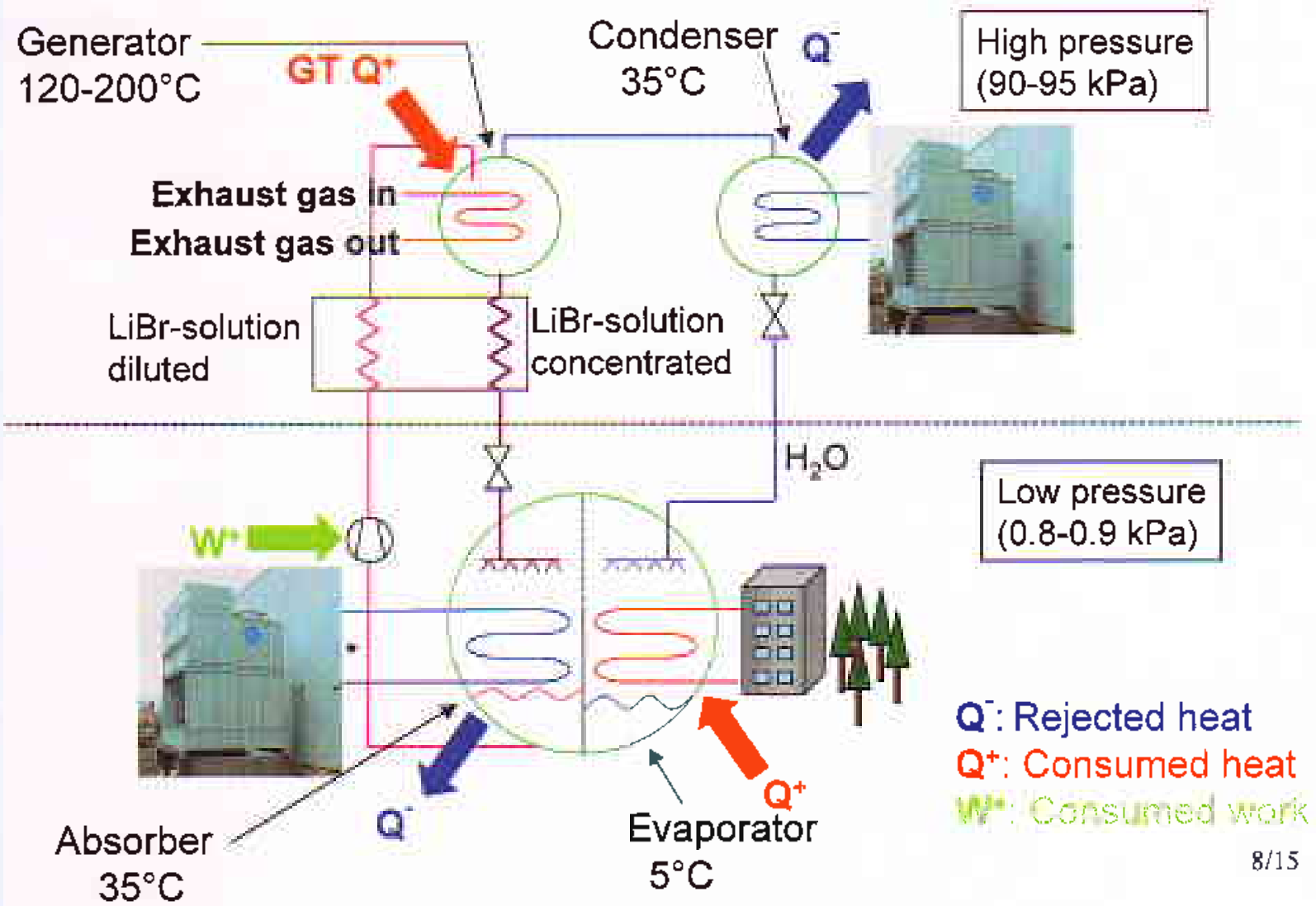




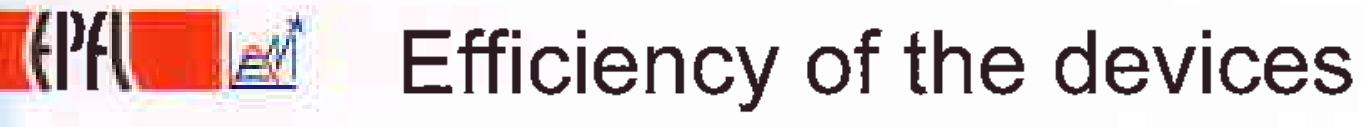

SOFC:

$$
\eta_{e l}=\frac{e l_{\text {SOFC }}}{F u e l \cdot L H V}=46-53 \%
$$

$\eta_{e l:}$ : Electrical efficiency of the SOFC [-]

el_SOFC: Electricity generated by the SOFC [kW]

Fuel: Fuel flow [mol/s]

$L H V$ : Lower heating value [kJ]

Absorption-chiller:

$$
C O P=\frac{\text { Cooling_load }}{\text { Heat_load }} \cong 1.15
$$

COP: Coefficient of performance [-]

Cooling_load: Cooling provided by the chiller [kJ]

Heat_load: Heat required by the chiller in the generator [kJ] ${ }^{9 / 15}$

\section{APf $\square \|^{*}$}

\section{MO-NLP}

Multi-objective optimization problem on two levels, investment and operational.

Min: Costs, $\mathrm{CO}_{2}$-emissions

Subject to: Thermodynamic models

Electricity balance SOFC part-load $\geq 0.3 *$ SOFC size 


\section{Decision variables}

1. Multi-objective genetic algorithm:

Configuration parameters: sizes and operating conditions: SOFC

\section{Absorption-chiller $(\mathrm{ACH})$ Heat-exchanger (HEX) Storage devices}

2. Linear optimization algorithm:

Optimal operation of: SOFC

Absorption-chiller

Storage tanks

Use backup-devices.

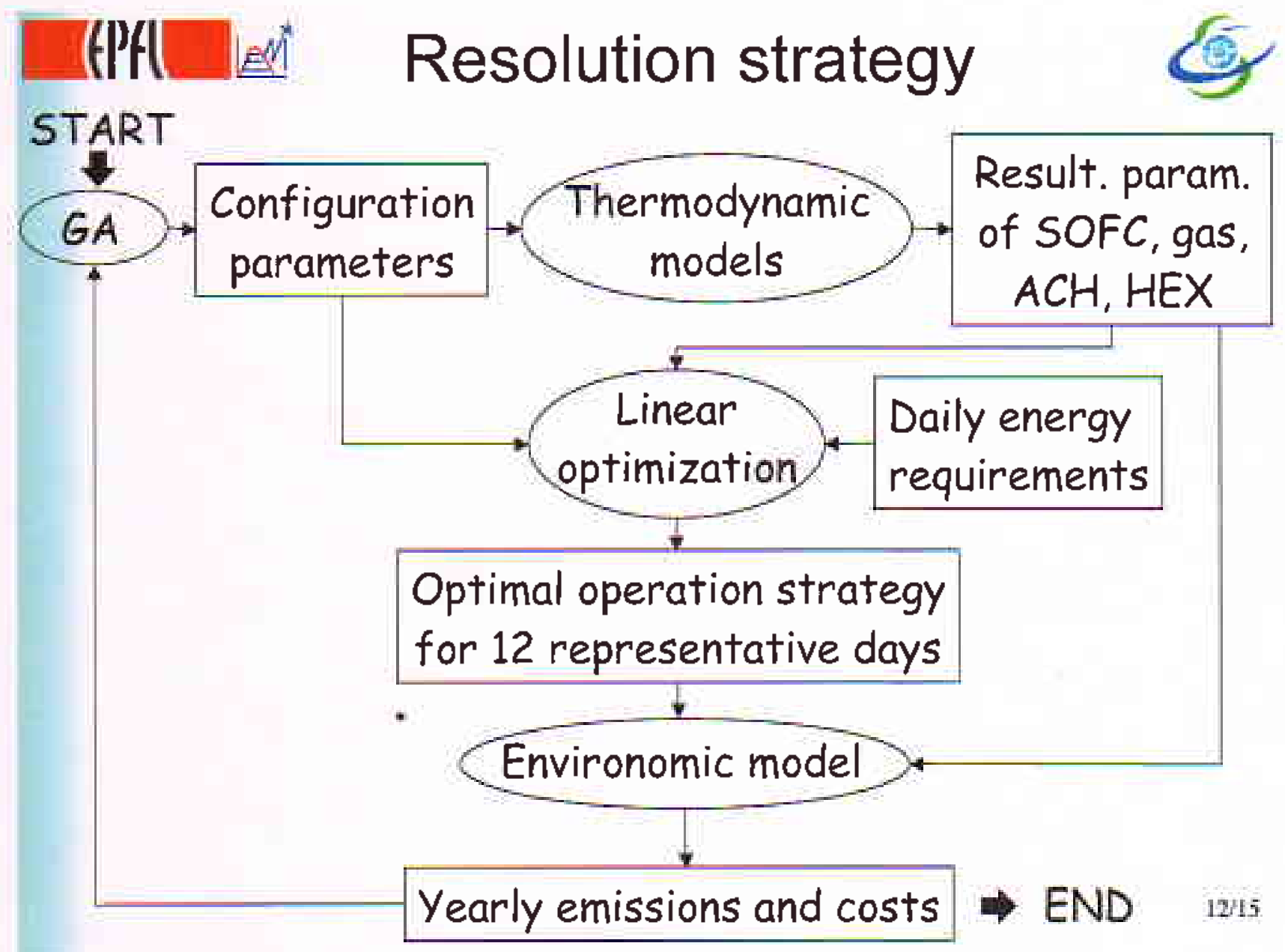




\section{Assumptions}

-All devices (except storage) perfectly insulated,

- The losses of the storage devices are maximum $10 \%$ at full charge,

- The temperature of the stocks is the same at the beginning and the end of the day,

-All the efficiencies and COP (coefficient of performance) are constant, regardless of the part load fraction,

- The values for costs and emissions are valid for Tōkyō.

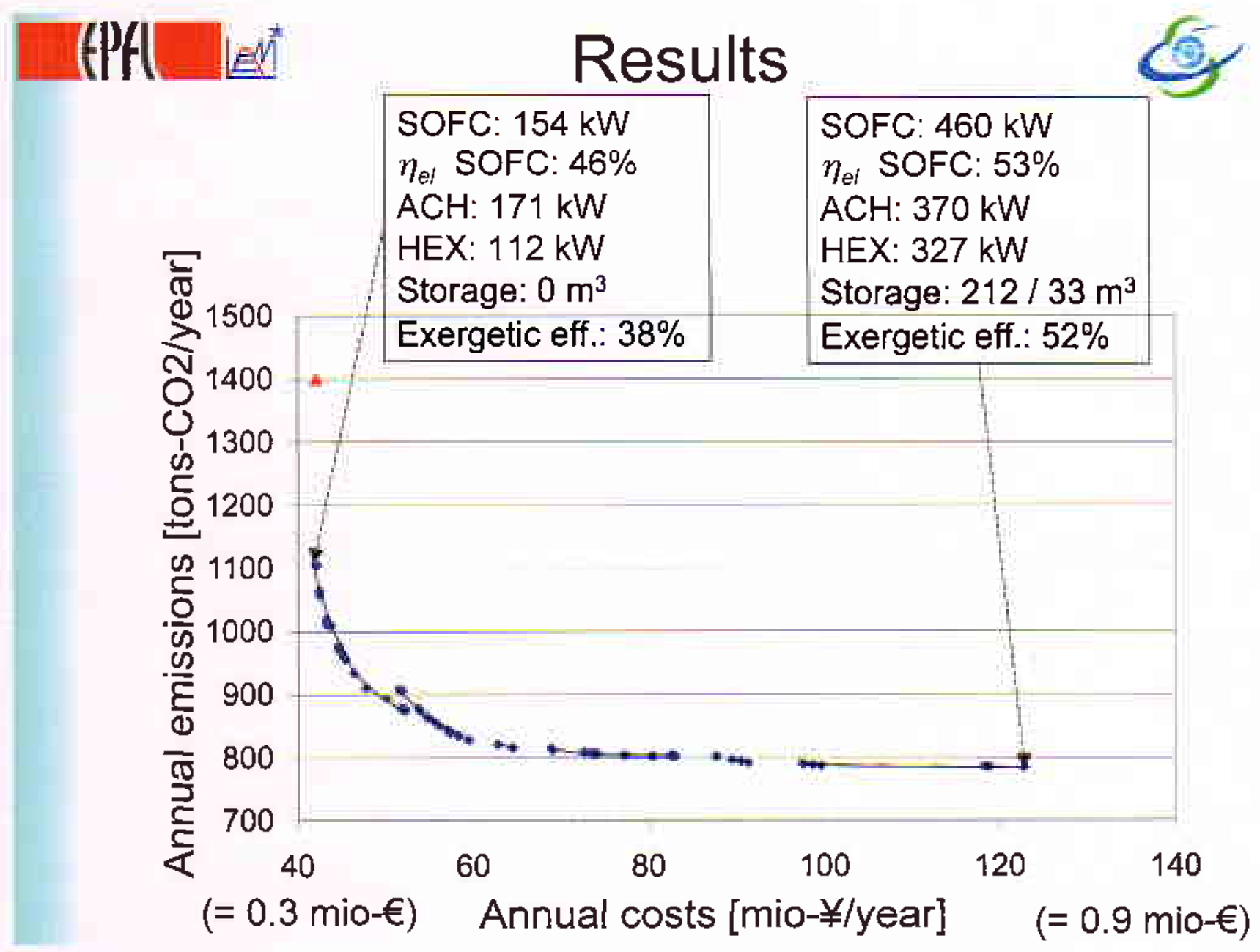




\section{Conclusions}

Output of the optimization problem

- Minus 40\% CO2-emissions by double the costs

Methodology

- Modular tool easy to adapt (other technologies, other regions, other buildings,...)

\section{Pareto curve}

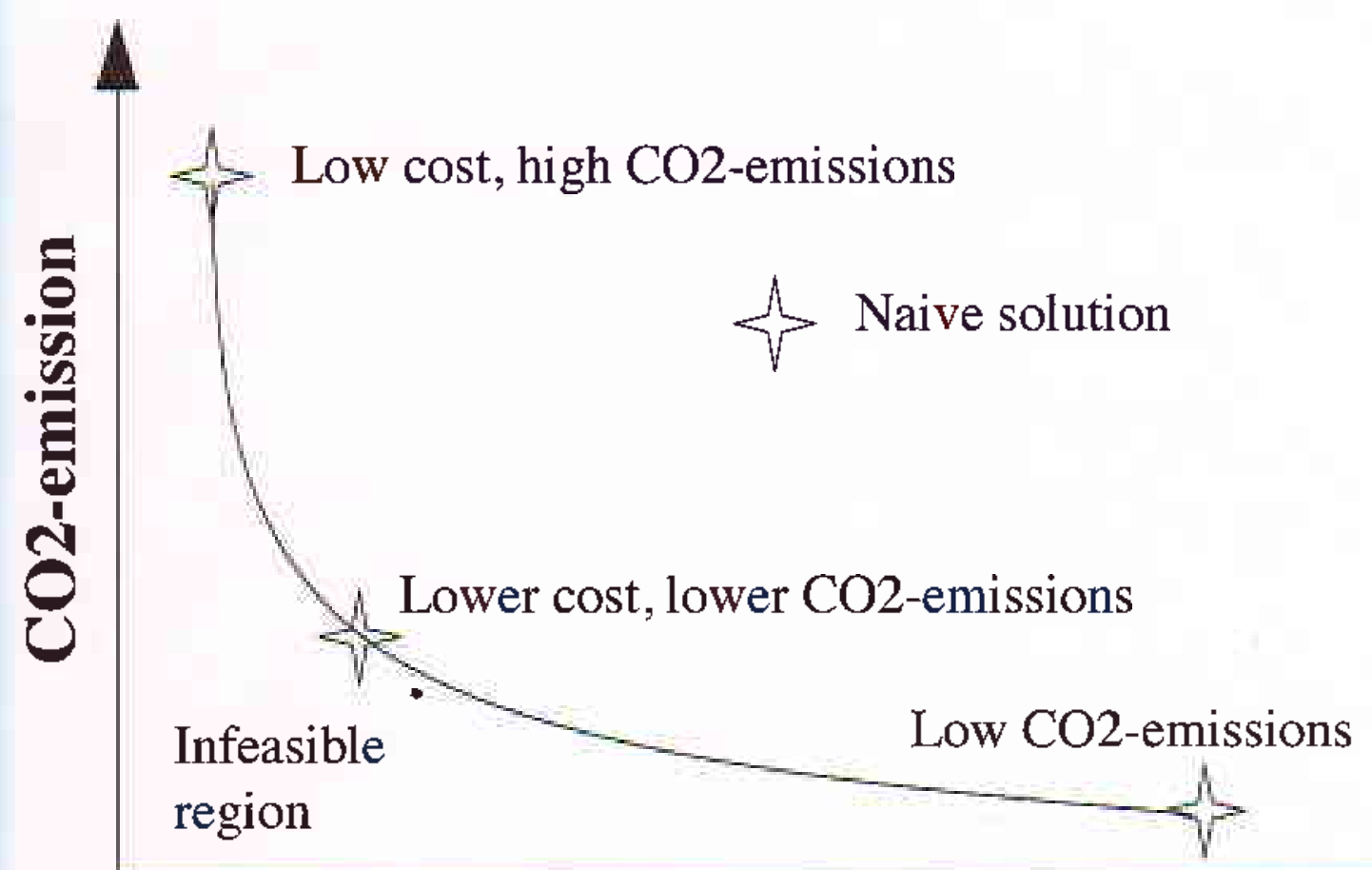

Cost 